\title{
A Polypyrrole Hybrid Material Self-Assembled with Porphyrin: Facial Synthesis and Enhanced Optical Limiting Properties
}

\author{
Yun Wang', Aijian Wang1, Peiyou Yang1, Wenxiu Hu', Xingnan Guo' ${ }^{1}$, Jing Zhang1, Cheng Li', \\ Chi Zhang ${ }^{*}$ \\ ${ }^{1}$ School of Chemistry and Chemical Engineering, Jiangsu University, Zhenjiang, China \\ ${ }^{2}$ Scientific Research Academy, Jiangsu University, Zhenjiang, China \\ Email: *chizhang@ujs.edu.cn,wajujs@ujs.edu.cn
}

How to cite this paper: Wang, Y., Wang, A.J., Yang, P.Y., Hu, W.X., Guo, X.N., Zhang, J., Li, C. and Zhang, C. (2017) A Polypyrrole Hybrid Material Self-Assembled with Porphyrin: Facial Synthesis and Enhanced Optical Limiting Properties. Journal of Materials Science and Chemical Engineering, 5, 26-43.

https://doi.org/10.4236/msce.2017.510003

Received: September 19, 2017

Accepted: October 27, 2017

Published: October 30, 2017

Copyright $\odot 2017$ by authors and Scientific Research Publishing Inc. This work is licensed under the Creative Commons Attribution International License (CC BY 4.0).

http://creativecommons.org/licenses/by/4.0/

\section{(c) (i) Open Access}

\begin{abstract}
Polypyrrole/porphyrin nanohybrid ( $\mathrm{PPy} / \mathrm{Tpp}(\mathrm{OH})_{4}$ nanohybrid) have been synthesized through a self-assembled approach, and the as-synthesized $\mathrm{PPy} / \mathrm{Tpp}(\mathrm{OH})_{4}$ nanohybrid are characterized by Fourier-transform infrared, $\mathrm{X}$-ray photoelectron spectroscopy, Raman spectroscopy, thermogravimetric analysis, Ultraviolet-visible absorption, scanning electron microscopy, and steady state fluorescence spectroscopic techniques. Formation of the $\mathrm{PPy} / \mathrm{Tpp}(\mathrm{OH})_{4}$ nanohybrid dramatically improved the solubility and processability of the PPy-based nano-material. The nonlinear optical (NLO) properties of PPy/Tpp $(\mathrm{OH})_{4}$ nanohybrid were measured by Z-scan at $532 \mathrm{~nm}$ with nanosecond laser pulse, the results indicating that $\mathrm{PPy} / \mathrm{Tpp}(\mathrm{OH})_{4}$ nanohybrid exhibits a enhanced NLO property in comparison with the benchmark PPy and $\operatorname{Tpp}(\mathrm{OH})_{4}$ due to a combination of mechanisms.
\end{abstract}

\section{Keywords}

PPy/Tpp $(\mathrm{OH})_{4}$ Nanohybrid, Self-Assemble, Z-Scan, Optical Limiting

\section{Introduction}

Optical limiters are a kind of materials which could help to protect naked eyes and photoelectric optical systems against the hostile lasers and attenuate the intensity of these lasers with their unique transient filtering actions (absorptive and refractive effects) [1]. Optical limiters could dramatically decrease intense incident laser beams and present weaker transmittance at high-intensity light while the irradiation pass through the optical limiters linearly under lower light 
intensities [2]. The nonlinear optical (NLO) performances of conjugated polymers (CPs) including polyaniline [3], polythiophene [4] and polypyrrole [5] have been reported extensively in the past three decades, due to their high conductivity, extensive $\pi$ electron delocalization and architectural flexibility. Polypyrrole and its derivatives do trigger greater attention due to their excellent processability, eco-friendly and eminent mechanical property [6]. However, the poor solubility and dispersion stability of polypyrrole materials occurred to be the first barrier for their application in nonlinear optical field [7]. Many efforts have been putted to solve this urgent issue, and one of the most effective methods is the functionalization of polypyrrole materials with soluble molecules [8]. In the present case, we synthesized modified polypyrrole (PPy) with a modification of previously reported method [9].

Porphyrins have continued to be of considerable interest since they were discovered, because they possess many appealing chemical and photochemical performances, such as high thermostability, intense visible absorption bands, long-lived excited state, extensive $\pi$-electron delocalization, besides, they are ubiquitous in nature and they are non-toxic and harmless, commendably [10] [11]. Porphyrins have been promising materials for the applications in photodynamic therapy, electrochemical sensors, data storage, optical switching and nonlinear optics [12] [13]. The particular $\pi$-conjugated structure endows porphyrins great NLO properties, and the optical limiting behaviors of porphyrins has been widely studied and they have exhibited attractive results, what's more, porphyrins are often used in supramolecular self-assembly [14].

In this article, we firstly synthesized a novel PPy self-assembly with 4,4',4",4"'-(porphyrin-5,10,15,20-tetrayl)tetraphenol $\left(\mathrm{Tpp}(\mathrm{OH})_{4}\right)\left(\mathrm{PPy} / \mathrm{Tpp}(\mathrm{OH})_{4}\right)$ nanohybrid in accordance with the previously reported method [15]. The resultant $\mathrm{PPy} / \mathrm{Tpp}(\mathrm{OH})_{4}$ nanohybrid was characterized by Fourier-transform infrared, X-ray photoelectron spectroscopy, Raman spectroscopy, scanning electron microscopy to ensure the successful formation, while Ultraviolet-visible absorption and steady state fluorescence were carried out to demonstrate the efficient electron and energy transfer between $\mathrm{Tpp}(\mathrm{OH})_{4}$ moieties and PPy units, thermogravimetric analysis was conducted to study the thermostability of resultant samples. The NLO absorption properties of PPy, Tpp $(\mathrm{OH})_{4}$ and $\mathrm{PPy} / \mathrm{Tpp}(\mathrm{OH})_{4}$ nanohybrid were characterized by Z-scan measurements with a $4 \mathrm{~ns}$ (fwhm) 532 nm pulses. It turned out that $\mathrm{PPy} / \mathrm{Tpp}(\mathrm{OH})_{4}$ nanohybrid displayed an enhanced NLO property compared with the benchmark $\mathrm{Tpp}(\mathrm{OH})_{4}$ moieties and PPy units.

\section{Experimental Section}

\subsection{Materials and Instruments}

Pyrrole and p-hydroxy benzaldehyde were purchased from Sinopharm Chemical Reagent Co. Ltd. China, ammonium persulfate (APS), trichloromethane, dichloromethane, tetrabutyl ammonium iodide (TBAI) as well as dimethyl sulfoxide (DMSO) were purchased from Sigma-Aldrich Chemical Co. All chemicals were 
of analytical reagent grade and used without further purification, unless otherwise stated. Ultrapure water was used throughout the study. Tpp $(\mathrm{OH})_{4}$ was synthesis by literature procedures [16].

Fourier-transform infrared (FT-IR) spectra were recorded on a Nicolet 5700 FT-IR spectrometer with $\mathrm{KBr}$ pellets in the $400-4000 \mathrm{~cm}^{-1}$ region, and all the FT-IR samples were prepared as $\mathrm{KBr}$ discs using spectroscopic grade $\mathrm{KBr}$ at room temperature. Ultraviolet-visible (UV-Vis) spectra were recorded using a Shimadzu UV-2550 spectrophotometer in the range of $200-800 \mathrm{~nm}$. Steady state fluorescence spectra were recorded on a Shimadzu RF-5300 PC fluorescence spectrophotometer using a Xe lamp as the light source, samples were dissolved in dry DMF, filtered, transferred to a long quartz cell, and then capped and deoxygenated by bubbling with $\mathrm{N}_{2}$ before measurement. The surface composition was determined by X-ray photoelectron spectroscopy (XPS) using a Thermo ESCALAB 250 spectrometer with a monochromatic Al Ka X-ray source and a charge neutralizer. The decomposition patterns of samples were taken on a Q600 SDTTGA/DSC thermogravimetric analyzer under an $\mathrm{N}_{2}$ flow rate of 100 $\mathrm{mL} / \mathrm{min}$ at a heating rate of $10^{\circ} \mathrm{C} / \mathrm{min}$ from room temperature to $800^{\circ} \mathrm{C}$. Scanning electron microscopy (SEM) of sample was measured with FLA650F type of the FEI company. Raman spectra of resultant products were carried out with a Micro Raman System RM3000 spectrometer with excitation laser wavelength at $532 \mathrm{~nm}$, the laser light was focused onto samples by using a microscope equipped with a $100 \times$ objective. The NLO performances of the as-prepared samples were measured by performing Z-scan measurements using a Nd:YAG laser (Continuum, Surelite II) with $4 \mathrm{~ns}$ (fwhm) $532 \mathrm{~nm}$ pulses, operating at repetition rates of $2 \mathrm{~Hz}$ [17].

\subsection{Synthesis of PPy}

PPy was prepared from pyrrole monomer and p-hydroxy benzaldehyde by chemical oxidative method at room temperature in the presence of APS (Scheme 1). A typical procedures as follows: $1.26 \mathrm{~mL}$ of pyrrole monomer, $365.30 \mathrm{mg}$ of p-hydroxy benzaldehyde and $100.00 \mathrm{mg}$ of TBAI were distilled in $30.00 \mathrm{~mL}$ of icy trichloromethane ultrapure water solution (volume rate of trichloromethane:ultrapure water $=1: 1$ ) in a beaker under magnetic stirring with ice-water bath, and then $2.00 \mathrm{~g}$ of APS dissolved in $10.00 \mathrm{~mL}$ of icy trichloromethane ultrapure water solution was added dropwise into the system, and then stirred at $3^{\circ} \mathrm{C}$ with ice-water bath for another $24 \mathrm{~h}$. After the addition of APS solution, the initial colorless solution became darker and eventually precipitated as a dark sediment at the bottom of the beaker. The solution was filtered and washed with ultrapure water and $\mathrm{CH}_{2} \mathrm{Cl}_{2}$ several times until the filtrate was clear. The residual black solid was dried under vaccum for $48 \mathrm{~h}$ at room temperature to afford dry PPy powder.

\subsection{Synthesis of PPy/Tpp $(\mathrm{OH})_{4}$ Nanohybrid}

$\mathrm{PPy} / \mathrm{Tpp}(\mathrm{OH})_{4}$ nanohybrid was prepared with $\mathrm{Tpp}(\mathrm{OH})_{4}$, pyrrole monomer and 
p-hydroxy benzaldehyde by a self-assemble method. A typical synthesis routes as follows: $30.00 \mathrm{mg}$ of TBAI was dissolved in $60.00 \mathrm{~mL}$ of icy trichloromethane ultrapure water solution in a beaker under magnetic stirring with ice-water bath (solution A). Solution B was prepared by adding $0.10 \mathrm{~mL}$ of pyrrole monomer, $30.34 \mathrm{mg}$ of p-hydroxy benzaldehyde and $25.26 \mathrm{mg}$ of $\mathrm{Tpp}(\mathrm{OH})_{4}$ dissolved into $30.00 \mathrm{~mL}$ of icy solution $\mathrm{A}$ in a beaker under magnetic stirring with ice-water bath (solution B). $170.00 \mathrm{mg}$ of APS was dissolved in $15.00 \mathrm{~mL}$ of icy solution A in a beaker under magnetic stirring with ice-water bath to procedure solution $\mathrm{C}$. The $\mathrm{B}$ and $\mathrm{C}$ solutions were cooled to $3^{\circ} \mathrm{C}$ and then mixed $\mathrm{B}$ and $\mathrm{C}$ quickly in a $100.00 \mathrm{~mL}$ beaker with magnetic stirring at $3^{\circ} \mathrm{C}$ with ice-water bath. After stirring for $24 \mathrm{~h}$, the solution was filtered and washed with ultrapure water $(20.00$ $\mathrm{mL} \times 4)$ and $\mathrm{CH}_{2} \mathrm{Cl}_{2}(10.00 \mathrm{~mL} \times 6)$ and then dried under vaccum for $48 \mathrm{~h}$ at room temperature to afford dry $\mathrm{PPy} / \mathrm{Tpp}(\mathrm{OH})_{4}$ nanohybrid powder.

\section{Results and Discussion}

\subsection{Characterization}

Figure 1 represents the FT-IR spectra of as-synthesized PPy, Tpp $(\mathrm{OH})_{4}$ and $\mathrm{PPy} / \mathrm{Tpp}(\mathrm{OH})_{4}$ nanohybrid in the range of 4000 to $400 \mathrm{~cm}^{-1}$, which can correspondingly characterize their chemical structures. In the FT-IR spectrum of PPy, all the characteristic peaks of polypyrrole and phenolic hydroxyl group were observed which confirmed the successful formation of PPy, where the peak at $797.73 \mathrm{~cm}^{-1}$ can be attributed to $\mathrm{C}-\mathrm{H}$ wagging and the $925.08 \mathrm{~cm}^{-1}$ is assigned to out of plane ring deformation [18]. The peak around $1048.62 \mathrm{~cm}^{-1}$ is related to $=$ $\mathrm{C}-\mathrm{H}$ in plane vibrations, $1159.19 \mathrm{~cm}^{-1}$ for $\mathrm{C}-\mathrm{N}$ bond and $1688.41 \mathrm{~cm}^{-1}$ for $\mathrm{C}=\mathrm{N}$ bond, $1548.10 \mathrm{~cm}^{-1}$ for stretching vibrations of $\mathrm{C}=\mathrm{C}$ bond, the peak at 3115.18 $\mathrm{cm}^{-1}$ is ascribed to $\mathrm{N}-\mathrm{H}$ stretching vibrations [19]. Where the peak at 1281.20 $\mathrm{cm}^{-1}$ is due to the successful function of phenolic hydroxyl group [20]. Compared to PPy, the FT-IR spectrum of $\mathrm{PPy} / \mathrm{Tpp}(\mathrm{OH})_{4}$ nanohybrid displayed two

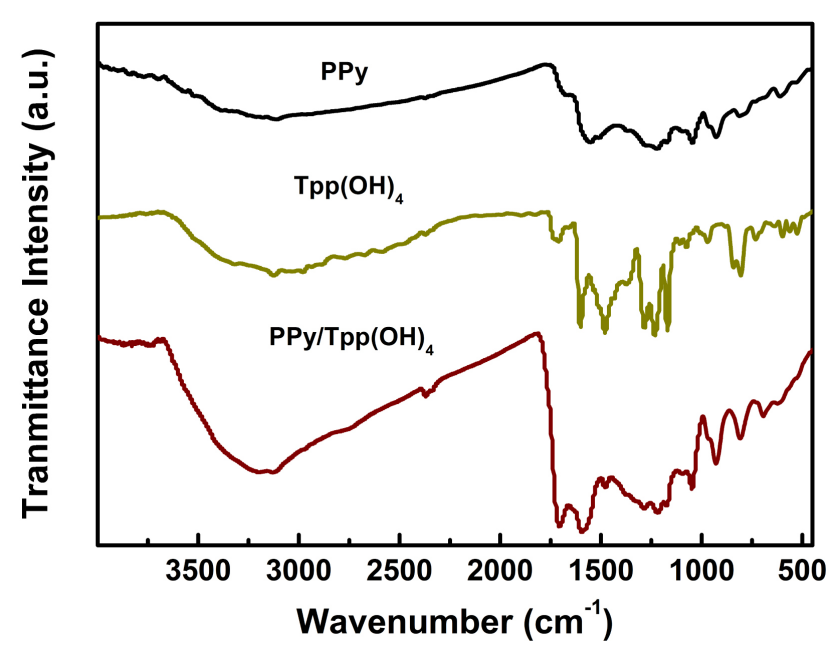

Figure 1. FT-IR spectra of $\mathrm{PPy}, \mathrm{Tpp}(\mathrm{OH})_{4}, \mathrm{PPy} / \mathrm{Tpp}(\mathrm{OH})_{4}$ nanohybrid. 
new peaks at 1712.05 and $2358.71 \mathrm{~cm}^{-1}$ that are coincident with those displayed by the porphyrin unit [21], conforming the successful functionalization of PPy with porphyrin via self-assemble.

To further characterize the structure features of pristine $\mathrm{PPy}$ and $\mathrm{PPy} / \mathrm{Tpp}(\mathrm{OH})_{4}$ nanocomposite, Raman spectrum was carried out with excitation laser wavelength at $532 \mathrm{~nm}$. In Figure 2, a typical intense tangential resonance absorption band ( $\mathrm{G}$ band) at $1559 \mathrm{~cm}^{-1}$ and a defect band (D band) at $1375 \mathrm{~cm}^{-1}$ was found in the spectrum of pristine PPy, which is corresponding to the $\mathrm{C}=\mathrm{C}$ backbone stretching and the ring stretching mode of PPy, respectively [22]. The Raman spectrum of $\mathrm{PPy} / \mathrm{Tpp}(\mathrm{OH})_{4}$ nanocomposite gives rise to two principal spectral bands of interest, observed at Raman shift of $1578 \mathrm{~cm}^{-1}$ (G band) and $1356 \mathrm{~cm}^{-1}$ (D band), respectively. A comparison between the observed D and $\mathrm{G}$ bands for PPy before and after modification with $\mathrm{Tpp}(\mathrm{OH})_{4}$ is given in Table 1, compared with PPy, the blue-shift of the D band and the red-shift of the $G$ band for $\mathrm{PPy} / \mathrm{Tpp}(\mathrm{OH})_{4}$ nanohybrid are similar to previous reported functionalization of RGO by porphyrins, may result from the electron transfer from $\mathrm{Tpp}(\mathrm{OH})_{4}$ to PPy [23]. In the present case, the intensity ratio of the $\mathrm{D}$ band to that of the $\mathrm{G}$ band $\left(I_{\mathrm{D}} / I_{\mathrm{G}}\right)$ for $\mathrm{PPy} / \mathrm{Tpp}(\mathrm{OH})_{4}$ nanohybrid of 0.69 is significantly decreased than that of PPy (0.79), which is corresponding to the previous work by Wang et al. [24].

The TGA spectrum was carried out to investigate the thermal stability of

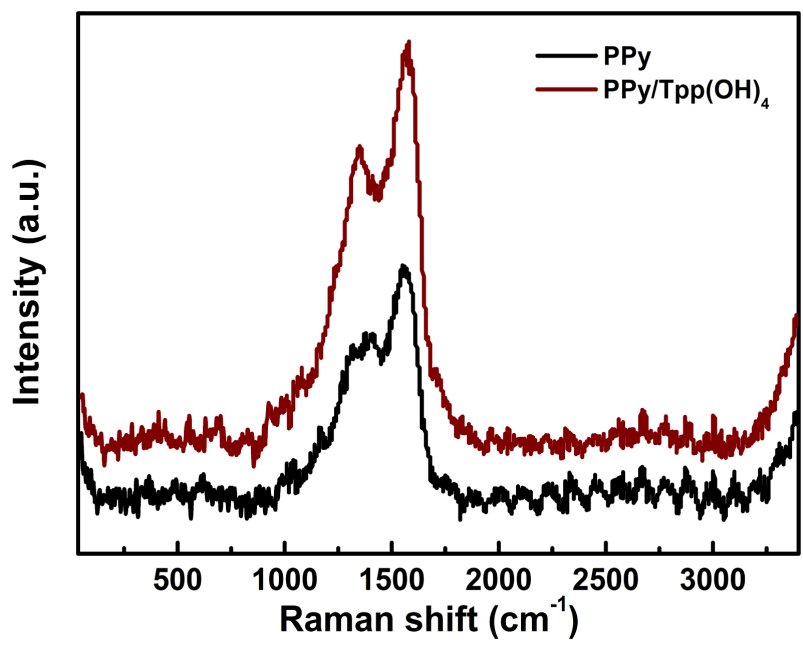

Figure 2. Raman spectra for the PPy before and after modification with $\operatorname{Tpp}(\mathrm{OH})_{4}$.

Table 1. Raman spectral data obtained for the pristine $\mathrm{PPy}$ and $\mathrm{PPy} / \mathrm{Tpp}(\mathrm{OH})_{4}$ nanohybrid.

\begin{tabular}{cccc}
\hline \multirow{2}{*}{ Samples } & \multicolumn{2}{c}{ Frequency $\left(\mathrm{cm}^{-1}\right)$} & $I_{\mathrm{D}} / I_{\mathrm{G}}$ \\
\cline { 2 - 3 } & $\mathrm{D}$ band & $\mathrm{G}$ band & 0.79 \\
\hline $\mathrm{PPy}$ & 1375 & 1559 & 0.69 \\
$\mathrm{PPy} / \mathrm{Tpp}(\mathrm{OH})_{4}$ & 1356 & 1578 & \\
\hline
\end{tabular}


as-received $\mathrm{PPy}, \mathrm{Tpp}(\mathrm{OH})_{4}$ and $\mathrm{PPy} / \mathrm{Tpp}(\mathrm{OH})_{4}$ nanohybrid by temperature gravity analysis under an $\mathrm{N}_{2}$ atmosphere. The obtained thermograms have been shown in Figure 3. It was observed that PPy exhibits a typical three-step degradation behaviour. In the first step, a soft mass loss (9.7\%) was found at $30^{\circ} \mathrm{C}$ $134^{\circ} \mathrm{C}$, which could be attributed to the evaporation of the moisture and organic molecules present in the PPy chains [25]. Secondly, there is no obvious mass loss at the temperature range of $134^{\circ} \mathrm{C}-230^{\circ} \mathrm{C}$. In the third step, another decomposition $(27.8 \%)$ was observed at $230^{\circ} \mathrm{C}-800^{\circ} \mathrm{C}$, which could be mainly ascribed to degradation of the polymer chains [26]. Tpp $(\mathrm{OH})_{4}$ and $\mathrm{PPy} / \mathrm{Tpp}(\mathrm{OH})_{4}$ nanohybrid display analogical traces with $\mathrm{PPy}$, the stabilization time (from $180^{\circ} \mathrm{C}$ $\left.430^{\circ} \mathrm{C}, 250 \mathrm{~min}\right)$ in the second step of $\operatorname{Tpp}(\mathrm{OH})_{4}$ is longer than PPy (96 min), which may attribute to the stable porphine macrocycle of $\mathrm{Tpp}(\mathrm{OH})_{4}$. After the self-assemble of $\mathrm{Tpp}(\mathrm{OH})_{4}$, the residue weight of $\mathrm{PPy} / \mathrm{Tpp}(\mathrm{OH})_{4}$ nanohybrid is heavier than that of pristine $\mathrm{PPy}$, which might ascribe to the function of $\mathrm{Tpp}(\mathrm{OH})_{4}[27]$.

As shown in Figure 4, the XPS spectrum was carried out to evaluate the elemental composition and the functionality of the PPy, which provides essential and useful information for the successful self-assemble functionality of the $\mathrm{Tpp}(\mathrm{OH})_{4}$ moieties onto the surface of PPy. All these two samples (PPy and $\left.\mathrm{PPy} / \mathrm{Tpp}(\mathrm{OH})_{4}\right)$ provide $\mathrm{C} 1 \mathrm{~s}, \mathrm{~N} 1 \mathrm{~s}$ and $\mathrm{O}$ 1s peaks in the XPS survey spectra. However, the intensity of $\mathrm{N} 1 \mathrm{~s}$ peak is stronger than pristine PPy after the functionality of $\mathrm{Tpp}(\mathrm{OH})_{4}$ while the $\mathrm{C} 1 \mathrm{~s}$ is weaker than pure PPy, which provide a evidence of the successful formation of $\operatorname{PPy} / \mathrm{Tpp}(\mathrm{OH})_{4}$ nanohybrid [28]. (The enhanced intensity of $\mathrm{N} 1 \mathrm{~s}$ peak and the weaker intensity of $\mathrm{C} 1 \mathrm{~s}$ of $\mathrm{PPy} / \mathrm{Tpp}(\mathrm{OH})_{4}$ nanohybrid could be obviously observed in Appendix Figure $\mathrm{S} 1)$.

The high-resolution C 1s and N 1s XPS spectra of PPy and PPy/Tpp $(\mathrm{OH})_{4}$

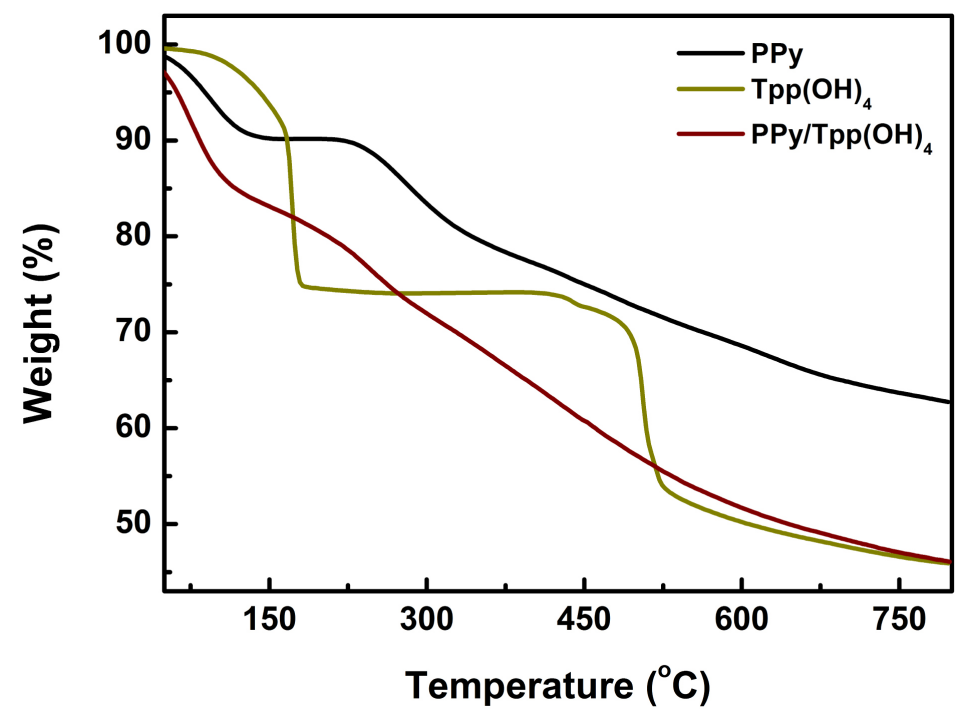

Figure 3. TGA curves of $\mathrm{PPy}, \mathrm{Tpp}(\mathrm{OH})_{4}$ and $\mathrm{PPy} / \mathrm{Tpp}(\mathrm{OH})_{4}$ nanohybrid under $\mathrm{N}_{2}$ atmosphere. 


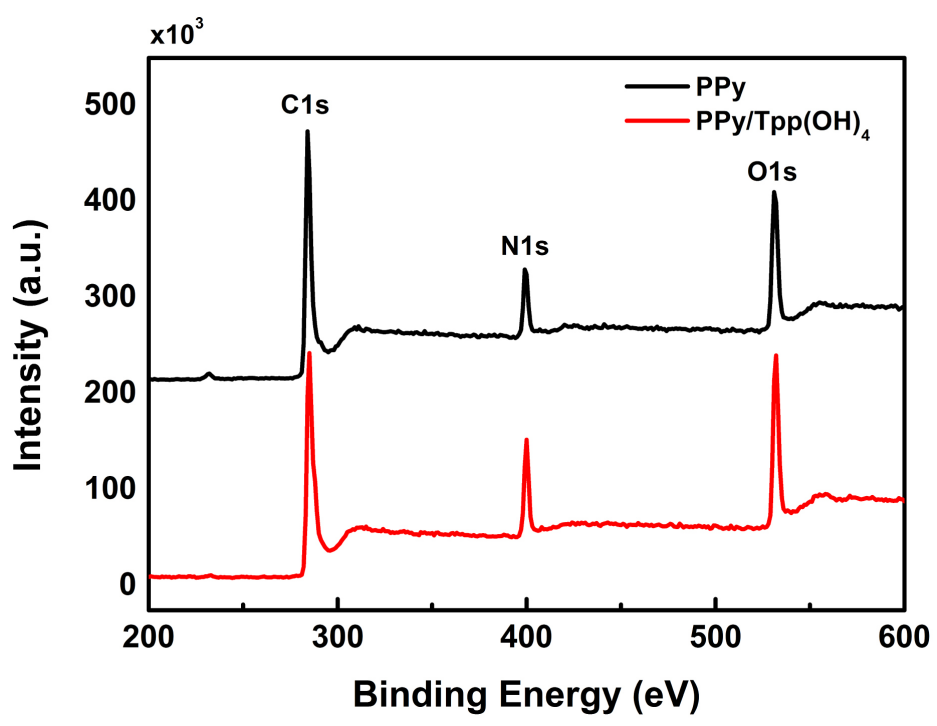

Figure 4. XPS survey scans of PPy and $\mathrm{PPy} / \mathrm{Tpp}(\mathrm{OH})_{4}$ nanohybrid.

nanohybrid were characterized to investigate the bonding state. As is shown in Figure 5(A), the C 1s XPS spectrum of PPy displays five components located at $286.33 \mathrm{eV}, 285.30 \mathrm{eV}, 284.68 \mathrm{eV}, 284.26 \mathrm{eV}$ and $283.77 \mathrm{eV}$ respectively, which corresponding to $\mathrm{C}=\mathrm{N}, \mathrm{C}-\mathrm{N}, \mathrm{C}-\mathrm{OH}, \mathrm{C}=\mathrm{C}$ and $\mathrm{C}-\mathrm{C} / \mathrm{C}-\mathrm{H}$ bonds respectively [29]. What need to be pointed out that, after the introduction of porphyrin moiety, the C 1s XPS spectrum of PPy/Tpp $(\mathrm{OH})_{4}$ demonstrates five different components at $287.74 \mathrm{eV}, 285.76 \mathrm{eV}, 285.00 \mathrm{eV}, 284.39 \mathrm{eV}$ and $283.87 \mathrm{eV}$ in Figure $5(\mathrm{~B})$, which are assigned to $\mathrm{C}=\mathrm{N}, \mathrm{C}-\mathrm{N}, \mathrm{C}-\mathrm{OH}, \mathrm{C}=\mathrm{C}$ and $\mathrm{C}-\mathrm{C} / \mathrm{C}-\mathrm{H}$ bonds respectively [30], which should be emphasize that, the $\mathrm{C}=\mathrm{N}, \mathrm{C}-\mathrm{N}$ bonds of $\mathrm{PPy} / \mathrm{Tpp}(\mathrm{OH})_{4}$ nanohybrid shows the red-shift of $1.41 \mathrm{eV}$ and $0.46 \mathrm{eV}$ respectively, when compared with PPy. In Figure 5(C), the high-resolution N 1s XPS spectra of PPy provide a further evidence about the presence of the porphyrin moieties on the surface of PPy [31]. PPy exhibits two peaks at $400.21 \mathrm{eV}$ and $399.63 \mathrm{eV}$ ascribing to the $\mathrm{N}$ atoms of $\mathrm{C}=\mathrm{N}$ and $\mathrm{C}-\mathrm{N}$ bonds respectively [32]. In completely contrast to PPy, the corelevel N 1s XPS spectrum of PPy/Tpp $(\mathrm{OH})_{4}$ nanocomposite (in Figure 5(D)) shows two different peaks located at $400.08 \mathrm{eV}$ (the $\mathrm{N}$ atoms of $\mathrm{C}=\mathrm{N}$ bonds) and $399.45 \mathrm{eV}$ (the $\mathrm{N}$ atoms of $\mathrm{C}-\mathrm{N}$ bonds), and there is a significantly intensity decrease of the $\mathrm{N}$ 1s peak due to the different chemical environments [33]. The surface morphological structures for the PPy before and after functionality with porphyrin moieties were investigated by SEM analysis, the results was exhibited in Figure 6. As shown in Figure 6(A) and Figure 6(B), PPy nano-material displays a typical smooth nanosheet SEM image with an average diameter of $1-2 \mu \mathrm{m}$. On the contrary, after the self-assemble measures with porphyrin moieties, $\operatorname{PPy} / \mathrm{Tpp}(\mathrm{OH})_{4}$ nanohybrid presents a different morphology in the Figure 6(C) and Figure 6(D), the SEM image of that $\mathrm{PPy} / \mathrm{Tpp}(\mathrm{OH})_{4}$ is rough, which may be ascribed to the functionality of $\mathrm{Tpp}(\mathrm{OH})_{4}$ moieties, the dark plots occured in Figure 6(D) were regarded as porphyrin units [34]. Furthermore, the average diameter of $\mathrm{PPy} / \mathrm{Tpp}(\mathrm{OH})_{4}$ 

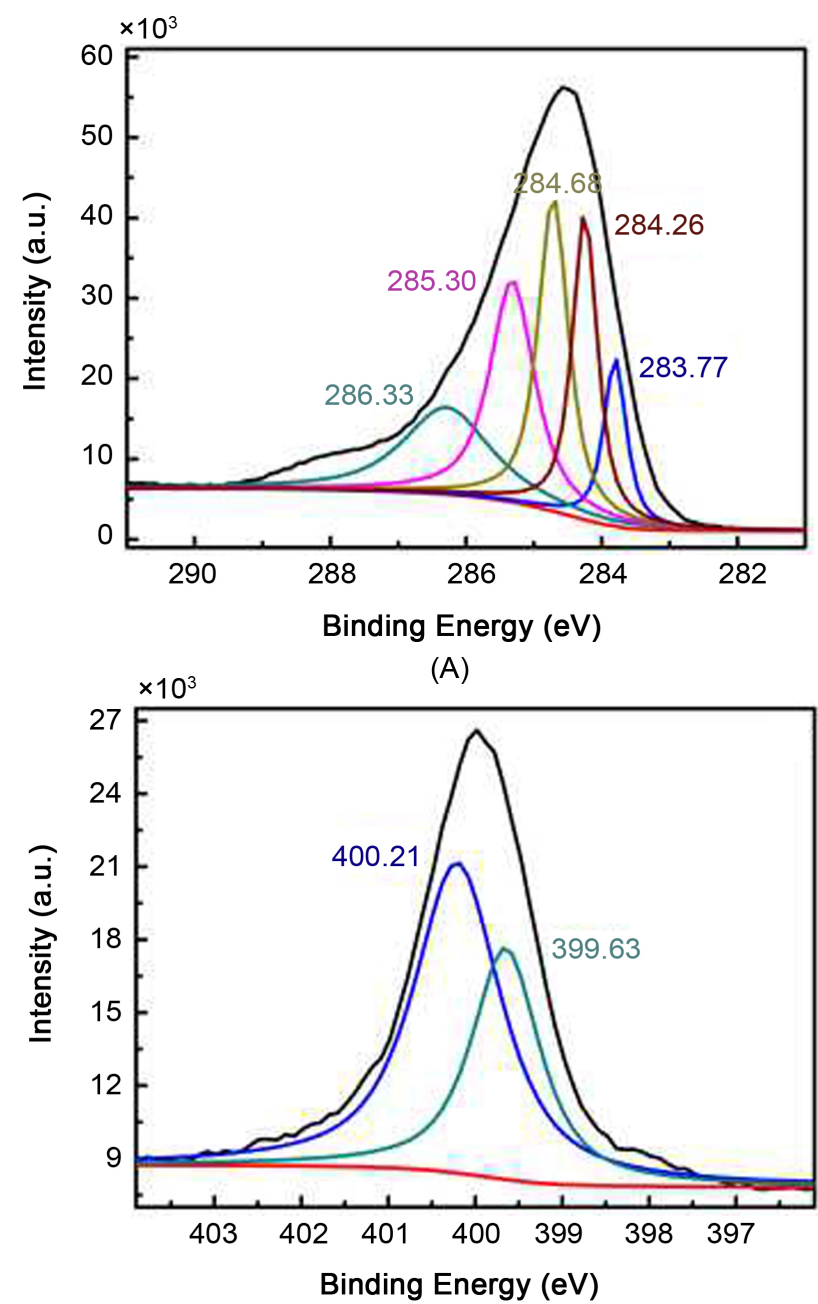

(C)

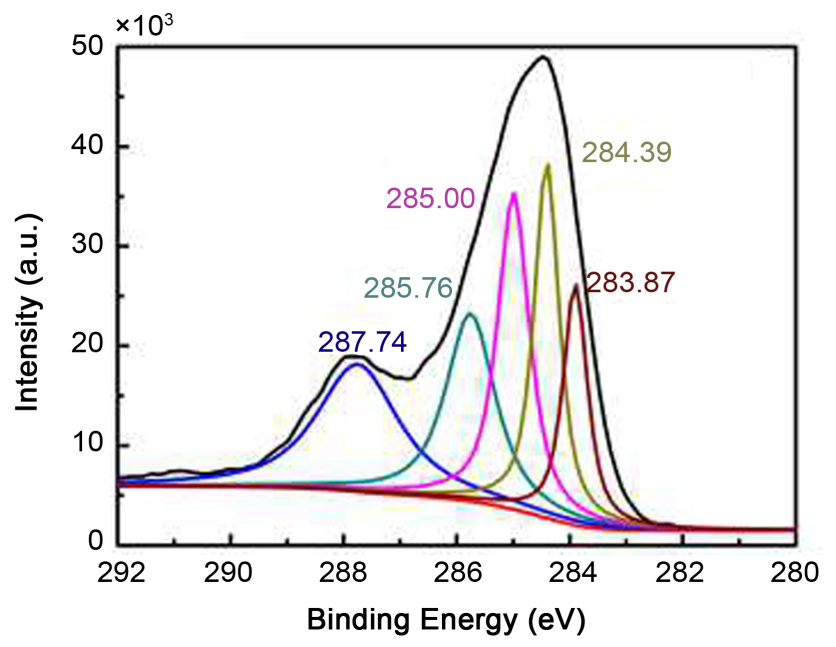

(B)

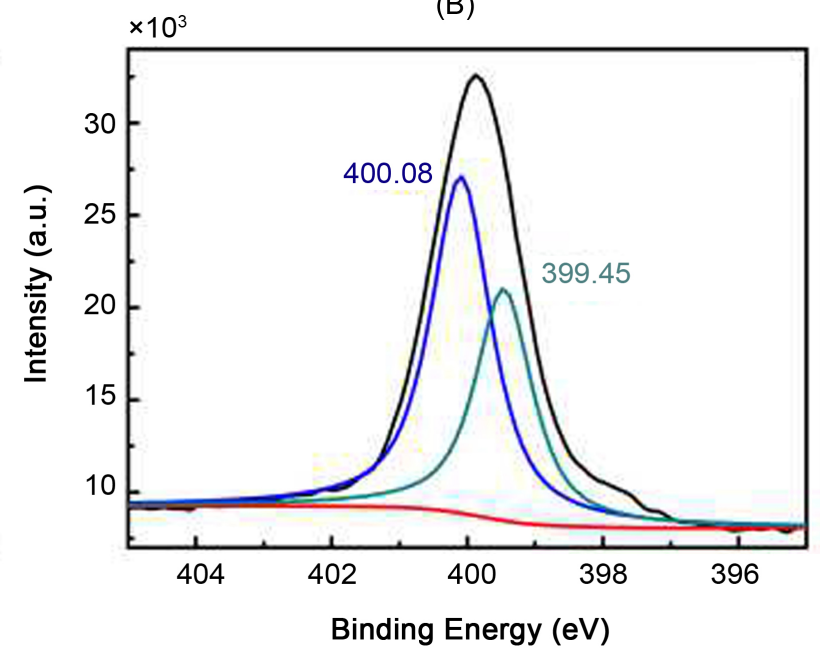

(D)

Figure 5. The high-resolution C 1s XPS spectra of PPy (A) and PPy/Tpp $(\mathrm{OH})_{4}(\mathrm{~B})$ as well as N 1s XPS spectra of PPy (C) and $\mathrm{PPy} / \mathrm{Tpp}(\mathrm{OH})_{4}(\mathrm{D})$.

nanohybrid aggrandized significantly. From what have been discussed above, the conclusion is the PPy/Tpp $(\mathrm{OH})_{4}$ nanocomposite has been successfully synthesized.

\subsection{Photophysical Properties}

At the aim to explore the interactions between PPy and Tpp $(\mathrm{OH})_{4}$ units, UV-Vis absorption spectrum and fluorescence methods were carried out, as depicted in Figure 7 and Figure 8. The UV-Vis absorption spectrum of $\mathrm{PPy}, \mathrm{Tpp}(\mathrm{OH})_{4}$, and $\mathrm{PPy} / \mathrm{Tpp}(\mathrm{OH})_{4}$ nanohybrid in DMSO was depicted in Figure 7. PPy shows a strong absorption peak at around $281 \mathrm{~nm}$ and a weak absorption peak at 424 $\mathrm{nm}$. At the same time, a typical porphyrin spectrum of $\mathrm{Tpp}(\mathrm{OH})_{4}$ was displayed with a vigoroso Soret band at $420 \mathrm{~nm}$ together with four weaker Q bands between 500 and $630 \mathrm{~nm}$, which are consist with porphyrin analogues [35], because the effect of PPy absorption at the porphyrin peak positions is relatively 


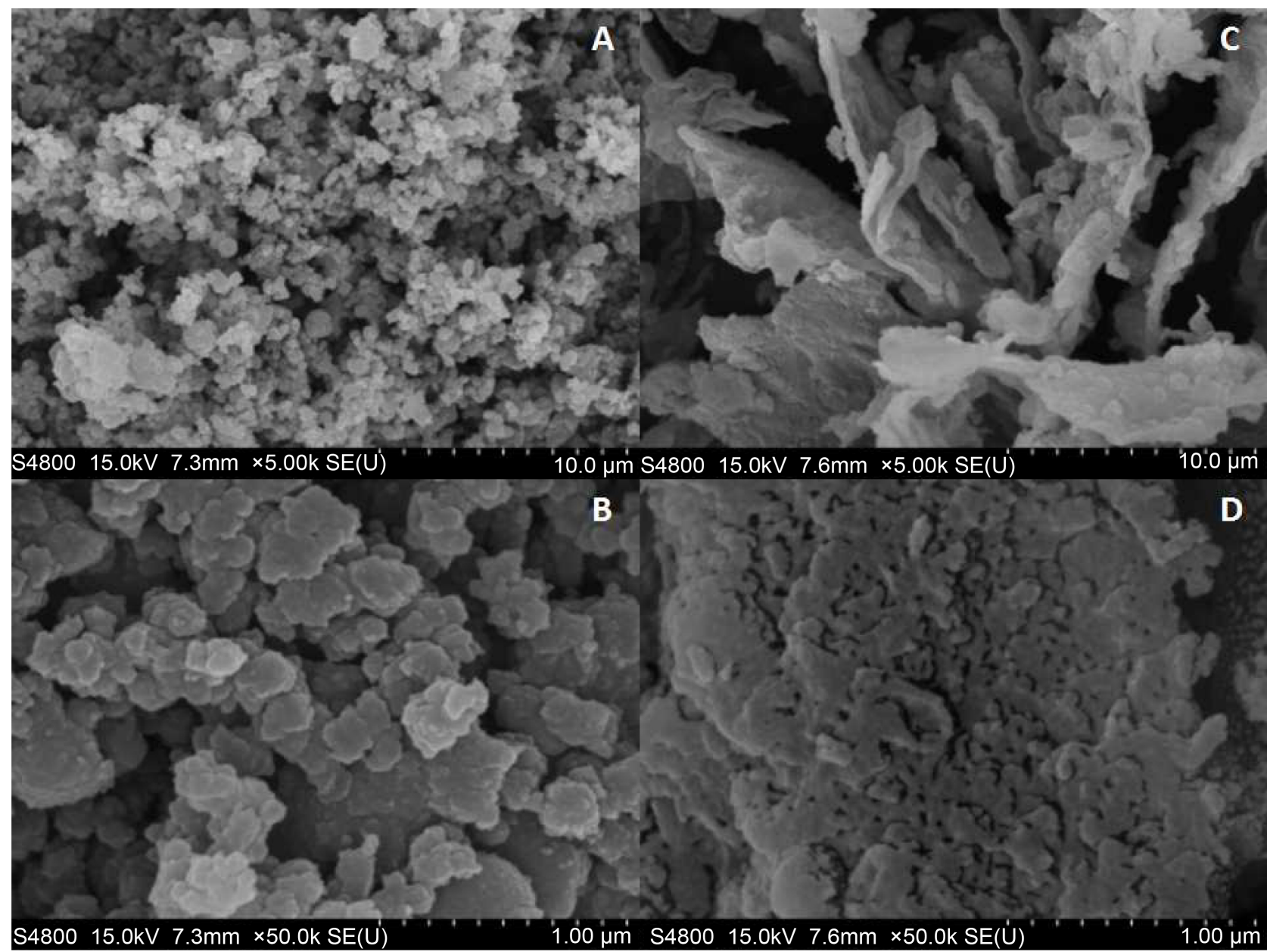

Figure 6. SEM images of as-synthesized PPy ((A), (B)) and PPy/Tpp(OH)4 nanohybrids ((C), (D)).

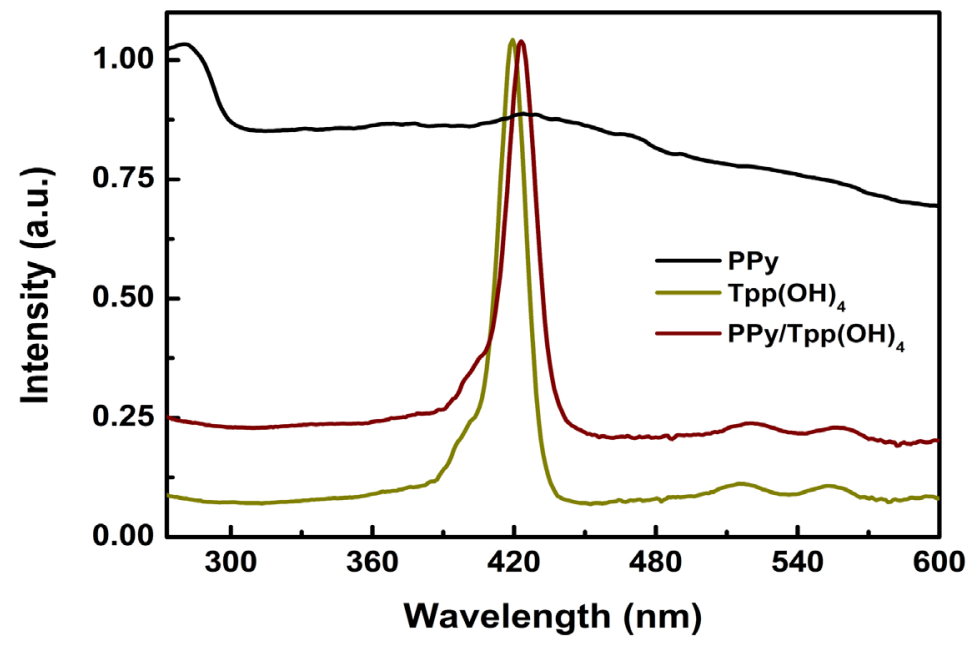

Figure 7. UV-Vis absorption spectra of $\mathrm{PPy}, \mathrm{Tpp}(\mathrm{OH})_{4}$ and $\mathrm{PPy} / \mathrm{Tpp}(\mathrm{OH})_{4}$ nanohybrid, in DMSO.

weak, the UV-Vis spectrum of $\mathrm{PPy} / \mathrm{Tpp}(\mathrm{OH})_{4}$ nanohybrid in DMSO is generally semblable to that of $\mathrm{Tpp}(\mathrm{OH})_{4}[36]$, while the Soret band peak of $\mathrm{PPy} / \mathrm{Tpp}(\mathrm{OH})_{4}$ 


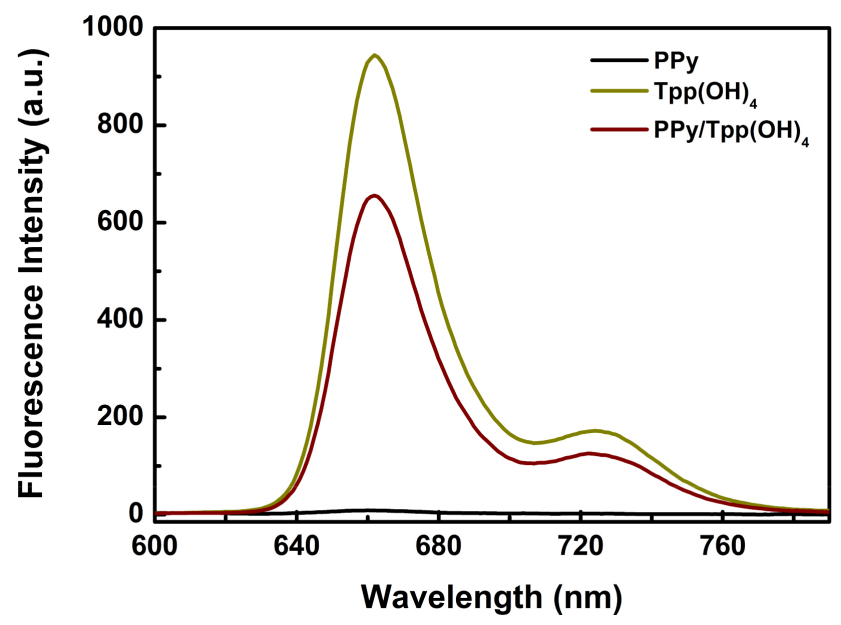

Figure 8. Fluorescence spectroscopic changes observed for PPy, $\mathrm{Tpp}(\mathrm{OH})_{4}$ and $\mathrm{PPy} / \mathrm{Tpp}(\mathrm{OH})_{4}$ nanohybrid in DMSO with the excitation wavelength of $423 \mathrm{~nm}$.

nanohybrid was found at $423 \mathrm{~nm}$ with a red-shift of $3 \mathrm{~nm}$, in addition, the intensity of PPy/Tpp $(\mathrm{OH})_{4}$ nanohybrid is only about $83.2 \%$ of that of Tpp $(\mathrm{OH})_{4}$, this provides unambiguous proof for the presence of the porphyrin units on the surface of PPy [37].

For the sake of exploring the excited-state interactions of $\mathrm{Tpp}(\mathrm{OH})_{4}$ and PPy in the hybrid, fluorescence spectra of $\operatorname{Tpp}(\mathrm{OH}) 4$, PPy, and PPy/Tpp $(\mathrm{OH})_{4}$ nanohybrid were obtained with the excitation of the porphyrin moiety at $423 \mathrm{~nm}$, as shown in Figure 8. The fluorescence of $\mathrm{Tpp}(\mathrm{OH})_{4}$ displays fluorescence features with a maximum and shoulder at 662 and $726 \mathrm{~nm}$ [38]. Nevertheless, PPy exhibits a nearly straight line at the excitation wavelength, which means PPy does not show a fluorescence signal. On the basis of this, the fluorescence of $\mathrm{PPy} / \mathrm{Tpp}(\mathrm{OH})_{4}$ nanohybrid must be from the porphyrin units merely, which provided a clear evidence for the occurrence of porphyrin moieties in the hybrid [39]. Besides, the steady-state fluorescence spectrum of $\mathrm{PPy} / \mathrm{Tpp}(\mathrm{OH})_{4}$ nanohybrid shares the same outlines as that of $\operatorname{Tpp}(\mathrm{OH})_{4}$, and is observed to be reduced strongly with a $69.6 \%$ fluorescence quantum yield, and the quenching of the $\mathrm{Tpp}(\mathrm{OH})_{4}$ moieties by PPy may be ascribed to the $\pi-\pi$ stacking interactions, moreover, the hydrogen bond interactions between PPy and porphyrin units might make some contributions to the quenching, demonstrates that the successful functionality of PPy.

\subsection{Nonlinear Optical Properties}

1) It has been proved that such polymers with conjugated structures have significant NLO performances [40], such as polythiophene and polyaniline, especially for polypyrrole. Because of its extensive $\pi$ electron delocalization, polypyrrole displays excellent NLO properties. However, the poor solubility of polypyrrole and its derivatives occurred to be the most dominating obstacle, as we all known, porphyrins exhibit outstanding NLO activities due to their macrocyclic 
conjugate structure [41], besides, as a well soluble organic compound, after the introduce of porphyrin moieties, the solubility of $\mathrm{PPy} / \mathrm{Tpp}(\mathrm{OH})_{4}$ nanohybrid has been improved greatly, therefore, it was of great interests to assess the NLO activity of $\mathrm{PPy} / \mathrm{Tpp}(\mathrm{OH})_{4}$ nanohybrid.

2) To get a better insight into the optimizations of the optical limiting effects of porphyrins assembled PPy, we measured open- and close-aperture Z-scan of $\mathrm{PPy}, \mathrm{Tpp}(\mathrm{OH})_{4}$ and $\mathrm{PPy} / \mathrm{Tpp}(\mathrm{OH})_{4}$ nanohybrid at $532 \mathrm{~nm}$ with $4 \mathrm{~ns}$ pulse laser irradiation [42], the results were shown in Figure 9 and Figure 10 respectively. From Figure 9, it can be seen that $\mathrm{Tpp}(\mathrm{OH})_{4}$ displays a valley-shaped NLO absorptive performance, it means that $\mathrm{Tpp}(\mathrm{OH})_{4}$ possesses a reverse saturation absorption (RSA) [43]. The NLO absorptive effects of PPy before and after modification of porphyrin exhibit a vividly contrary performance, PPy exhibits a

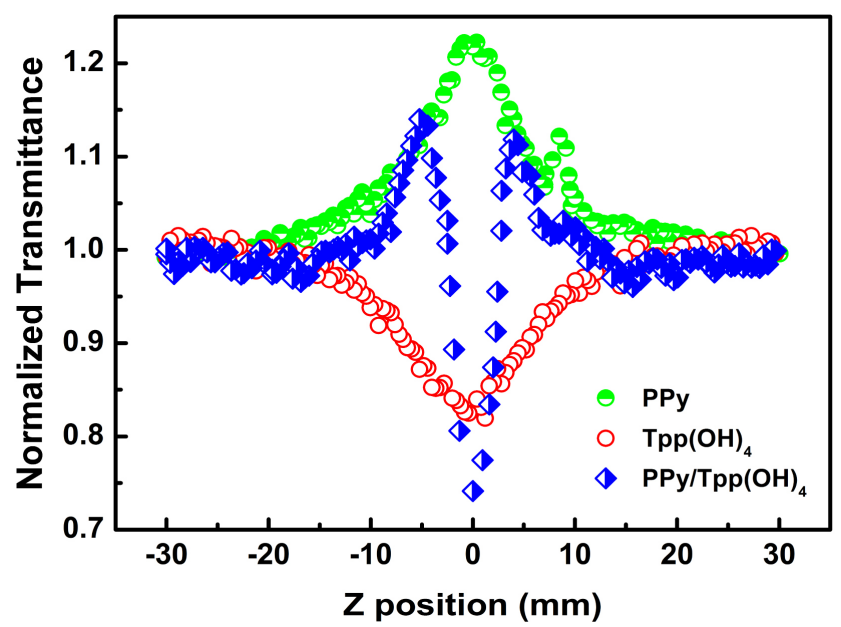

Figure 9. Normalized open-aperture Z-scan dates of PPy, $\mathrm{Tpp}(\mathrm{OH})_{4}$ and $\mathrm{PPy} / \mathrm{Tpp}(\mathrm{OH})_{4}$ nanohybrid in DMSO at a wavelength of $532 \mathrm{~nm}$ with $4 \mathrm{~ns}$ pulse durations.

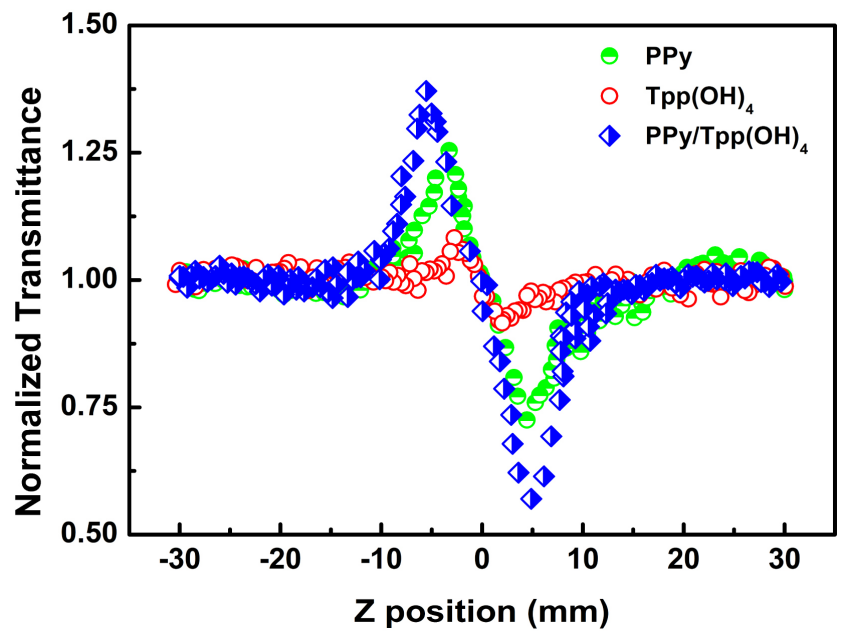

Figure 10. Normalized close-aperture Z-scan curves of PPy, $\mathrm{Tpp}(\mathrm{OH})_{4}$ and $\mathrm{PPy} / \mathrm{Tpp}(\mathrm{OH})_{4}$ nanohybrid in DMSO at a wavelength of $532 \mathrm{~nm}$ with $4 \mathrm{~ns}$ pulse durations. 
peak-shaped NLO absorptive behavior, it means that PPy possesses a saturation absorption (SA), while the open-aperture Z-scan result of $\mathrm{PPy} / \mathrm{Tpp}(\mathrm{OH})_{4}$ nanohybrid appears a typical valley-shaped NLO absorptive performance (RSA), the change of opening direction may be ascribed to the successful formation of $\mathrm{PPy} / \mathrm{Tpp}(\mathrm{OH})_{4}$ nanohybrid [44]. It is well-known that the depth/altitude of the valley/peak in the Z-scan curves was consisted to the extent of NLO activity [45], from Figure 9, it is no doubt that the depth of $\mathrm{PPy} / \mathrm{Tpp}(\mathrm{OH})_{4}$ nanohybrid was longer than the depth of $\mathrm{Tpp}(\mathrm{OH})_{4}$ and the altitude of PPy, which proves that the nonlinearity of PPy was tremendously improved by the intervenation of $\mathrm{Tpp}(\mathrm{OH})_{4}$.

Figure 10 exhibits the NLO refractive data for PPy, Tpp $(\mathrm{OH})_{4}$ and PPy/ $\mathrm{Tpp}(\mathrm{OH})_{4}$ nanohybrid at $532 \mathrm{~nm}$ with $4 \mathrm{~ns}$ pulse laser irradiation under close-aperture configuration [46]. All materials displays a pre-focal transmittance maximun (peak) followed by a post-focal transmittance minimum (valley) signal, this peak-valley signature demonstrates a negative nonlinearity and corresponding to the self-defocusing behavior [47]. Clearly, the differences between the normalized transmittance values and valley positions for $\mathrm{PPy} / \mathrm{Tpp}(\mathrm{OH})_{4}$ nanocomposite are larger than PPy and porphyrin unit. In a word, the as-prepared $\mathrm{PPy} / \mathrm{Tpp}(\mathrm{OH})_{4}$ nanocomposite exhibits the most optimum nonlinear refraction respond in the close-aperture $\mathrm{Z}$-scan measurement, as well.

In the present case, the Z-scan of PPy, Tpp $(\mathrm{OH})_{4}$ and PPy/Tpp $(\mathrm{OH})_{4}$ nanocomposite were measured under nanosecond pulse conditions at $532 \mathrm{~nm}$, in the nanosecond regime, PPy showed a typical SA effect, which mainly resulted from the superior electric conductivity [5] and excited-state absorption [9], while the porphyrin moiety $\mathrm{Tpp}(\mathrm{OH})_{4}$ exhibited a RSA performance, which might arise from the excited-state absorption [48], the result was interestingly semblable with other chromophore such as phthalocyanine and other porphyrin [49]. After the self-assembled synthesis of $\operatorname{PPy} / \mathrm{Tpp}(\mathrm{OH})_{4}$ nanocomposite, all of these combination mechanisms will play an indispensable role at strengthening the nonlinearity effect of as-synthesized $\operatorname{PPy} / \operatorname{Tpp}(\mathrm{OH})_{4}$ nanohybrid. What's more, in the $\mathrm{PPy} / \mathrm{Tpp}(\mathrm{OH})_{4}$ nanohybrid system, the donor-acceptor coactions between the porphyrin moieties and PPy triggered an intermolecular electron and/or energy transfer from the excited-state porphyrin to the ground-state PPy [50], this interaction gave rise to obvious fluorescence quenching and energy release, could contribute to the improved nonlinear optical performances of $\mathrm{PPy} / \mathrm{Tpp}(\mathrm{OH})_{4}$ nanohybrid. In addition, these different NLO mechanisms and the characteristic structure of $\mathrm{PPy} / \mathrm{Tpp}(\mathrm{OH})_{4}$ hybrid material were exhibited in Figure 11. The molecular structure and intermolecular coactions could be clearly observed in this picture.

\section{Conclusion}

In conclusion, $\mathrm{PPy} / \mathrm{Tpp}(\mathrm{OH})_{4}$ nanohybrid has been prepared through a self-assembled approach with pyrrole monomer and the porphyrin unit 


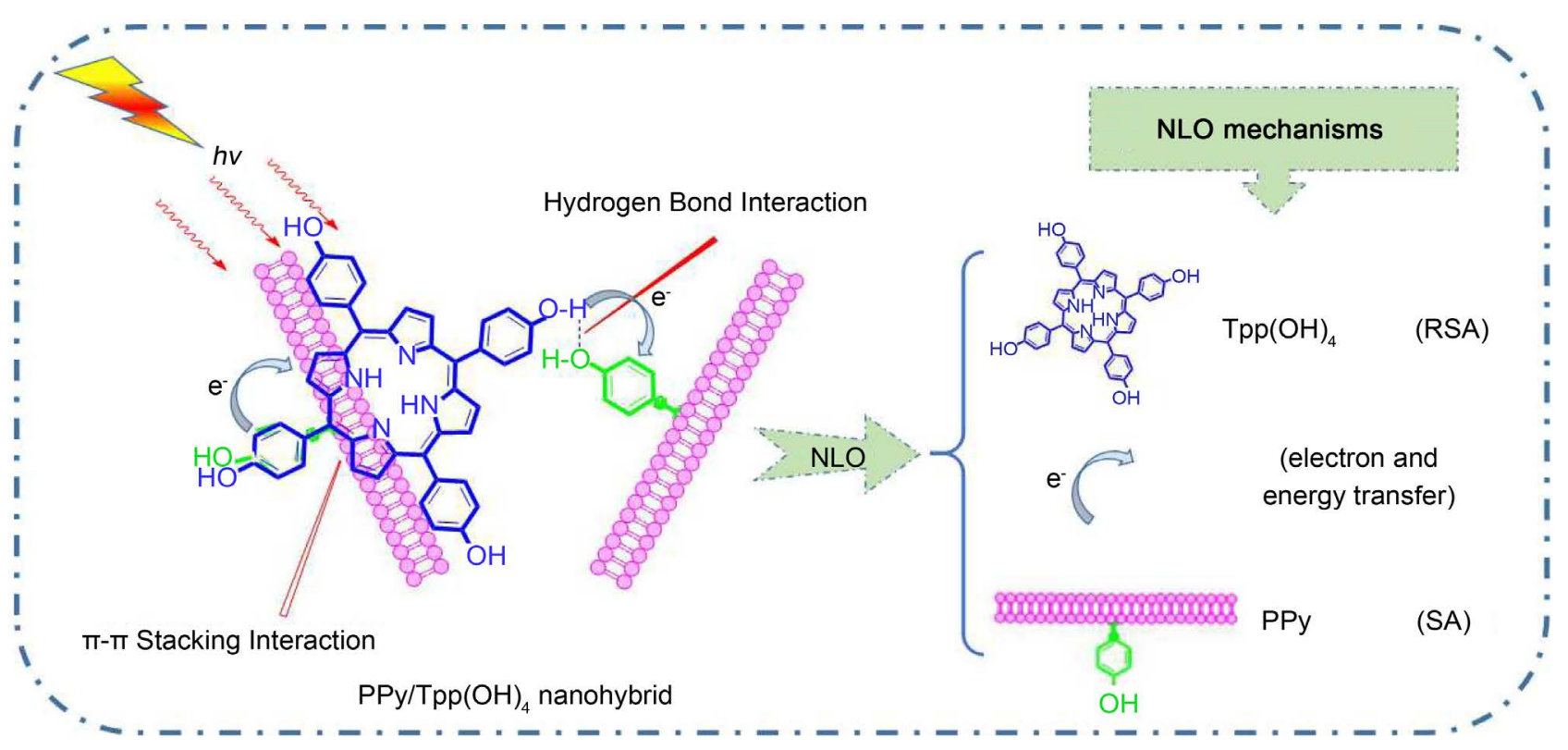

Figure 11. The schematic representation for structure and NLO mechanisms of $\mathrm{PPy} / \mathrm{Tpp}(\mathrm{OH})_{4}$ nanohybrid.

$\mathrm{Tpp}(\mathrm{OH})_{4}$, the nonlinearities of PPy/Tpp $(\mathrm{OH})_{4}$ nanohybrid as well as PPy and $\mathrm{Tpp}(\mathrm{OH})_{4}$ are characterized. The self-assembly formation of $\mathrm{PPy} / \mathrm{Tpp}(\mathrm{OH})_{4}$ nanohybrid was measured by FTIR, UV-Vis absorption, steady-state fluorescence, Raman, SEM, TGA and XPS spectroscopic techniques, and all results clearly manifest that the successful formation of $\mathrm{PPy} / \mathrm{Tpp}(\mathrm{OH})_{4}$ nanohybrid. The formation of $\mathrm{PPy} / \mathrm{Tpp}(\mathrm{OH})_{4}$ nanohybrid significantly improves the solubility and dispersion stability of the PPy-based materials in organic solvents. The steadystate fluorescence study demonstrate that there are tremendous hydrogen bond interactions, considerable $\pi-\pi$ stack interactions and numerous electron and/or energy transfer between porphyrin moieties and PPy units of PPy/Tpp $(\mathrm{OH})_{4}$ nanohybrid. The dramatically enhanced NLO property of $\mathrm{PPy} / \mathrm{Tpp}(\mathrm{OH})_{4}$ nanohybrid has been observed comparing with the benchmark PPy and $\mathrm{Tpp}(\mathrm{OH})_{4}$, which can be attributed to a combination mechanisms of PPy and porphyrin units, the electron and/or energy transfer also do some contributions. The present results should be useful for the development of organic-polymer nanocomposites with desired NLO properties.

\section{References}

[1] Torre, G.D.L., Vazquez, P., Lopez, F.A. and Torres, T. (2004) Role of Structural Factors in the Nonlinear Optical Properties of Phthalocyanines and Related Compounds. Chemical Reviews, 104, 3723-3750. https://doi.org/10.1021/cr030206t

[2] Zhang, L. and Wang, L. (2008) Recent Research Progress on Optical Limiting Property of Materials Based on Phthalocyanine, Its Derivatives, and Carbon Nanotubes. Journal of Materials Science, 43, 5692-5701. https://doi.org/10.1007/s10853-008-2826-4

[3] Sajeev, U.S., Nambuthiri, V.V., Salah, A., Nampoori, V.P.N. and Anantharaman, M.R. (2010) Studies on the Nonlinear Optical Properties of RF Plasma Polymerized Aniline thin Films by Open Aperture z-Scan Technique. Synthetic Metals, 160, 
15-16. https://doi.org/10.1016/j.synthmet.2010.06.004

[4] Lanzi, M. and Paganin, L. (2009) New Photosetting NLO-Active Polythiophenes with Enhanced Optical Stability. European Polymer Journal, 45, 1118-1126. https://doi.org/10.1016/j.eurpolymj.2009.01.013

[5] Ke, R., Zhang, X.M., Zhang, S.Y., Li, S.L., Mao, C.J., Niu, H.L., Song, J.M. and Tian, Y.P. (2015) Self-Catalytic Polymerization of Water-Soluble Selenium/Polypyrrole Nanocomposite and Its Nonlinear Optical Properties. Physical Chemistry Chemical Physics, 17, 27548-27557. https://doi.org/10.1039/C5CP04419G

[6] Zhou, C., Zhang, Y.W., Li, Y.Y. and Liu, J.P. (2013) Construction of High-Capacitance 3D CoO@Polypyrrole Nanowire Array Electrode for Aqueous Asymmetric Supercapacitor. Nano Letters, 13, 2078-2085. https://doi.org/10.1021/nl400378j

[7] Song, W.N., He, C.Y., Dong, Y.L., Zhang, W., Gao, Y.C., Wu, Y.Q. and Chen, Z.M. (2015) The Effects of Central Metals on the Photophysical and Nonlinear Optical Properties of Reduced Graphene Oxide-Metal(II) Phthalocyanine Hybrids. Physical Chemistry Chemical Physics, 17, 7149-7157. https://doi.org/10.1039/C4CP05963H

[8] Ye, Y.S., Chen, Y.N., Wang, J.S., Rick, J., Huang, Y.J., Chang, F.C. and Hwang, B.J. (2012) Versatile Grafting Approaches to Functionalizing Individually Dispersed Graphene Nanosheets Using RAFT Polymerization and Click Chemistry. Chemistry of Materials, 24, 2987-2997. https://doi.org/10.1021/cm301345r

[9] Luo, S.L., Liu, X.E., Wu, D.Q., Shi, G. and Mei, T. (2014) Tunable Conversion from Saturable Absorption to Reverse Saturable Absorption in Poly(pyrrole methine) Derivatives. Journal of Material Chemistry C, 2, 8850-8853. https://doi.org/10.1039/C4TC01627K

[10] Scandola, F., Chiorboli, C., Prodi, A., Iengo, E. and Alessio, E. (2006) Photophysical Properties of Metal-Mediated Assemblies of Porphyrins. Coordination Chemistry Reviews, 250, 1471-1496. https://doi.org/10.1016/j.ccr.2006.01.019

[11] Imahori, H. and Fukuzumi, S. (2004) Porphyrin- and Fullerene-Based Molecular Photovoltaic Devices. Advanced Functional Materials, 14, 525-536. https://doi.org/10.1002/adfm.200305172

[12] Wang, J.J., Zhou, Z.J., Bai, Y., Liu, Z.B., Li, Y., Wu, D., Chen, W., Li, Z.R. and Sun, C.C. (2012) The Interaction between Superalkalis (M3O, M $=\mathrm{Na}, \mathrm{K}$ ) and a C20F20 Cage Forming Superalkali Electride Salt Molecules with Excess Electrons inside the C20F20 Cage: Dramatic Superalkali Effect on the Nonlinear Optical Property. Journal of Material and Chemistry, 22, 9652-9657. https://doi.org/10.1039/c2jm15405f

[13] Huang, C., Hu, C.L., Xu, X., Yang, B.P. and Mao, J.G. (2013) Tl(VO)2O2(IO3)3: A New Polar Material with a Strong SHG Response. Dalton Transactions, 42, 7051-7058. https://doi.org/10.1039/c3dt33107e

[14] Liu, C.G. and Guan, X.H. (2013) Computational Study on Redox-Switchable Second-Order Nonlinear Optical Properties of Totally Inorganic Keggin-Type Polyoxometalate Complexes. Journal of Physical Chemistry C, 117, 7776-7783. https://doi.org/10.1021/jp400185a

[15] Wang, Y.Q., Shi, Y., Pan, L.J., Ding, Y., Zhao, Y., Li, Y., Shi, Y. and Yu, G.H. (2015) Dopant-Enabled Supramolecular Approach for Controlled Synthesis of Nanostructured Conductive Polymer Hydrogels. Nano Letters, 15, 7736-7741. https://doi.org/10.1021/acs.nanolett.5b03891

[16] Liu, Y.N., Jin, J.Y., Deng, H.P., Li, K., Zheng, Y.L., Yu, C.Y. and Zhou, Y.F. (2016) Protein-Framed Multi-Porphyrin Micelles for a Hybrid Natural-Artificial LightHarvesting Nanosystem. Angewandte Chemie, 128, 8084-8089. 
https://doi.org/10.1002/ange.201601516

[17] Wang, A.J., Long, L.L., Zhao, W., Song, Y.L., Humphrey, M.G., Cifuentes, M.P., Wu, X.Z., Fu, Y.S., Zhang, D.D., Li, X.F. and Zhang, C. (2013) Increased Optical Nonlinearities of Graphene Nanohybrids Covalently Functionalized by AxiallyCoordinated Porphyrins. Carbon, 53, 327-338.

[18] Jain, S., Karmakar, N., Shah, A., Kothari, D.C., Mishra, S. and Shimpi, N.G. (2017) Ammonia Detection of 1-D ZnO/Polypyrrole Nanocomposite: Effect of CSA Doping and Their Structural, Chemical, Thermal and Gas Sensing Behavior. Applied Surface Science, 396, 1317-1325.

[19] Mao, H., Ji, C.G., Liu, M.H., Sun, Y., Liu, D.L., Wu, S.Y., Zhang, Y. and Song, X.M. (2016) Hydrophilic Polymers/Polypyrrole/Graphene Oxide Nanosheets with Different Performance in Electrocatalytic Application to Simultaneous Determination of Dopamine and Ascorbic Acid. RSC Advances, 6, 11632-11639.

https://doi.org/10.1039/C6RA23341D

[20] Tabaciarova, J., Micusík, M., Fedorko, P. and Omastova, M. (2015) Study of Polypyrrole Aging by XPS, FTIR and Conductivity Measurements. Polymer Degradation and Stability, 120, 392-401.

[21] Khadka, R., Aydemir, N., Kesküla, A., Tamm, T., Travas-Sejdic, J. and Kiefer, R. (2017) Enhancement of Polypyrrole Linear Actuation with Poly(Ethylene Oxide). Synthetic Metals, 232, 1-7.

[22] Gong, F., Xu, X., Zhou, G. and Wang, Z.S. (2013) Enhanced Charge Transportation in a Polypyrrole Counter Electrode via Incorporation of Reduced Graphene Oxide Sheets for Dye-Sensitized Solar Cells. Physical Chemistry Chemical Physics, 15, 546-552. https://doi.org/10.1039/C2CP42790G

[23] Wang, A.J., Yu, W., Xiao, Z.G., Song, Y.L., Long, L.L., Cifuentes, M.P., Humphery, M.G. and Zhang, C. (2015) A 1,3-Dipolar Cycloaddition Protocol to Porphyrinfunctionalized Reduced Graphene Oxide with a Push-Pull Motif. Nano Research, 8, 870-886. https://doi.org/10.1007/s12274-014-0569-x

[24] Wang, A.J., Yu, W., Huang, Z.P., Zhou, F., Song, J.B, Song, Y.L., Long, L.L., Cifuentes, M.P., Humphery, M.G., Zhang, L., Shao, J.D. and Zhang, C. (2015) Covalent Functionalization of Reduced Graphene Oxide with Porphyrin by Means of Diazonium Chemistry for Nonlinear Optical Performance. Scientific Reports, 6, 1-12.

[25] Wang, J.J., Feng, M. and Zhan, H.B. (2013) Preparation, Characterization, and Nonlinear Optical Properties of Graphene Oxide-Carboxymethyl Cellulose Composite Films. Optics \& Laser Technology, 57, 84-89.

[26] Liu, M.Q., Zhao, J., Xiao, C.F., Quan, Q. and Li, X.F. (2016) PPy-Assisted Fabrication of $\mathrm{Ag} / \mathrm{TiO} 2$ Visible-Light Photocatalyst and Its Immobilization on PAN Fiber. Materials and Design, 104, 428-435.

[27] Balakumar, V. and Prakash, P. (2016) A Facile in Situ Synthesis of Highly Active and Reusable Ternary Ag-PPy-GO Nanocomposite for Catalytic Oxidation of Hydroquinone in Aqueous Solution. Journal of Catalysis, 344, 795-805.

[28] Yang, K., Gu, M.Y., Guo, Y.P., Pan, X.F. and Mu, G.H. (2009) Effects of Carbon Nanotube Functionalization on the Mechanical and Thermal Properties of Epoxy Composites. Carbon, 47, 1723-1737.

[29] Jaouhari, A.E., Filotas, D., Laabd, M., Kiss, A., Bazzaoui, E.A., Nagy, L., Nagy, G., Albourine, A., Martins, J.I., Wang, R. and Bazzaoui, M. (2016) SECM Investigation of Electrochemically Synthesized Polypyrrole from Aqueous Medium. Journal of Applied Electrochemistry, 46, 1199-1209.

https://doi.org/10.1007/s10800-016-1002-9 
[30] Osmieri, L., Videla, A.H.A.M. and Specchia, S. (2016) Optimization of a FeeNeC Electrocatalyst Supported on Mesoporous Carbon Functionalized with Polypyrrole for Oxygen Reduction Reaction under Both Alkaline and Acidic Conditions. International Journal of Hydrogen Energy, 41, 19610-19628.

[31] Yan, J., Huang, Y., Chen, X.F. and Wei, C. (2016) Conducting Polymers-NiFe2O4 Coated on Reduced Graphene Oxide Sheets as Electromagnetic (EM) Wave Absorption Materials. Synthetic Metals, 221, 291-298.

[32] Zhu, J.H., Li, Y.X., Chen, Y., Wang, J., Zhang, B., Zhang, J.J. and Blau, W.J. (2011) Graphene Oxide Covalently Functionalized with Zinc Phthalocyanine for Broadband optical Limiting. Carbon, 49, 1900-1905.

[33] Li, C.L., Chen, N., Zhao, Y.N., Li, R. and Feng, C.P. (2016) Polypyrrole-Grafted Peanut Shell Biological Carbon as a Potential Sorbent for Fluoride Removal: Sorption Capability and Mechanism. Chemosphere, 163, 81-89.

[34] Wang, A.J., Song, J.B, Huang, Z.P., Song, Y.L., Yu, W., Dong, H.L., Hu, W.P., Cifuentes, M.P., Humphery, M.G., Zhang, L., Shao, J.D. and Zhang, C. (2015) Multi-Walled Carbon Nanotubes Covalently Functionalized by Axially Coordinated Metal-Porphyrins: Facile Syntheses and Temporally Dependent Optical Performance. Nano Research, 9, 458-472. https://doi.org/10.1007/s12274-015-0928-2

[35] Liu, Z.B., Tian, J.G., Guo, Z., Ren, D.M., Du, F., Zheng, J.Y. and Chen, Y.S. (2008) Enhanced Optical Limiting Effects in Porphyrin-Covalently Functionalized Single-Walled Carbon Nanotubes. Advanced Materials, 20, 511-515. https://doi.org/10.1002/adma.200702547

[36] Li, H.P., Martin, R.B., Harruff, B.A., Carino, R.A., Allard, L.F. and Sun, Y.P. (2004) Single-Walled Carbon Nanotubes Tethered with Porphyrins: Synthesis and Photophysical Properties. Advanced Materials, 16, 896-900. https://doi.org/10.1002/adma.200306288

[37] Xu, Y.F., Liu, Z.B., Zhang, X.L., Wang, Y., Tian, J.G., Huang, Y., Ma, Y.F., Zhang, X.Y. and Chen, Y.S. (2009) A Graphene Hybrid Material Covalently Functionalized with Porphyrin: Synthesis and Optical Limiting Property. Advanced Materials, 21, 1275-1279. https://doi.org/10.1002/adma.200801617

[38] Zhang, C.C., Chen, P.L., Dong, H.L, Zhen, Y.G., Liu, M.H. and Hu, W.P. (2015) Porphyrin Supramolecular 1D Structures via Surfactant Assisted Self-Assembly. Advanced Materials, 27, 5379-5387.

[39] Wang, A.J., Fang, Y., Long, L.L., Song, Y.L., Yu, W., Zhao, W., Cifuentes, M.P., Humphrey, M.G. and Zhang, C. (2013) Facile Synthesis and Enhanced Nonlinear Optical Properties of Porphyrin-Functionalized Multi-Walled Carbon Nanotubes. Chemistry A European Journal, 19, 14159-14170. https://doi.org/10.1002/chem.201302477

[40] Hedge, P.K., Adhikari, A.V., manjunatha, M.G., Sandeep, C.S.S. and Philip, R. (2010) A New Donor-Acceptor Type Conjugative Poly\{2-[4-(1-Cyanoethenyl) phenyl]-3-(3,4-didodecyloxythiophen-2-yl)prop-2-enenitrile\}: Synthesis and NLO Studies. Synthesitic Metals, 160, 15-16.

[41] Liu, Z.B., Guo, Z., Zhang, X.L., Zheng, J.Y. and Tian, J.G. (2013) Increased Optical Nonlinearities of Multi-Walled Carbon Nanotubes Covalently Functionalized with Porphyrin. Carbon, 51, 419-426.

[42] Krisshna, M.B.M., Venkatramaiah, N., Venkatesan, R. and Rao, D.N. (2012) Synthesis and Structural, Spectroscopic and Nonlinear Optical Measurements of Graphene Oxide and Its Composites with Metal and Metal Free Porphyrins. Journal of Material Chemistry, 22, 3059-3068. https://doi.org/10.1039/c1jm14822b 
[43] Wang, L., Chen, T.L. and Jiang, J.Z. (2014) Controlling the Growth of Porphyrin Based Nanostructures for Tuning Third-Order NLO Properties. Nanoscale, 6, 1871-1878. https://doi.org/10.1039/C3NR05140D

[44] Pandey, R.K., Sandeep, C.S.S., Philip, R. and Lakshminarayanan, V. (2009) Enhanced Optical Nonlinearity of Polyaniline-Porphyrin Nanocomposite. Journal of Physical Chemistry C, 113, 8630-8634. https://doi.org/10.1021/jp808691v

[45] Huang, C.S., Li, Y.L., Song, Y.L, Li, Y.J., Liu, H.B. and Zhu, D.B. (2010) Ordered Nanosphere Alignment of Porphyrin for the Improvement of Nonlinear Optical Properties. Advanced Materials, 22, 3532-3536. https://doi.org/10.1002/adma.200904421

[46] Gupta, J., Vijayan, C., Mauurya, S.K. and Goswami, D. (2012) Ultrafast Nonlinear Optical Response of Carbon Nanotubes Functionalized with Water Soluble Porphyrin. Optics Communications, 285, 1920-1924.

[47] Nalla, V., Polavarapu, L., Manga, K.K., Goh, B.M., Loh, K.P., Xu, O.H. and Ji, W. (2010) Transient Photoconductivity and Femtosecond Nonlinear Optical Properties of a Conjugated Polymer-Graphene Oxide Composite. Nanotechnology, 21, 415203-415209. https://doi.org/10.1088/0957-4484/21/41/415203

[48] Hiroshi, H. and Sakata, Y. (1997) Donor-Linked Fullerenes: Photoinduced Electron Transfer and Its Potential Application. Advanced Materials, 9, 537-546. https://doi.org/10.1002/adma.19970090704

[49] Anusha, P.T., Swain, D., Hamad, S., Giribabu, L., Prashant, T.S., Tewari, S.P. and Rao, S.V. (2012) Ultrafast Excited-State Dynamics and Dispersion Studies of Third Order Optical Nonlinearities in Novel Corroles. The Journal of Physical Chemistry C, 116, 17828-17837. https://doi.org/10.1021/jp305497b

[50] Krishna, M.B.M., kumer, V.P., Venkatramaiah, N., Venkatesan, R. and Rao, D.N. (2011) Nonlinear Optical Properties of Covalently Linked Graphene-Metal Porphyrin Composite Materials. Applied Physics Letters, 98, Article No. 08116. https://doi.org/10.1063/1.3553500 


\section{Appendix}

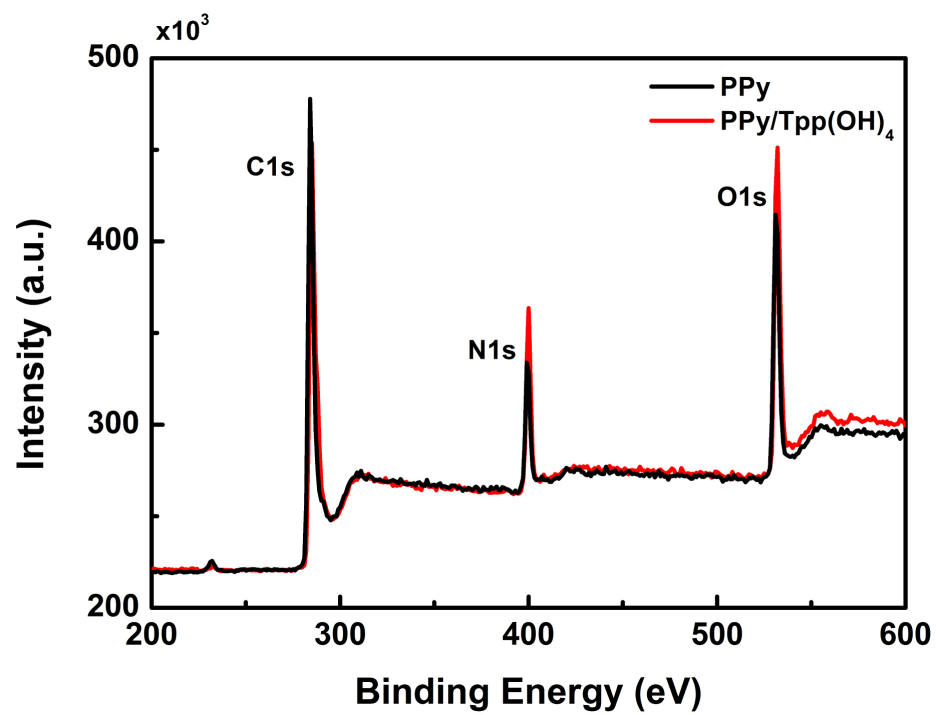

Figure S1. XPS survey scans of PPy and PPy/Tpp $(\mathrm{OH})_{4}$ nanohybrid. 